\title{
Enhancing College Oral English Teaching with Application of PBL
}

\author{
Qixin Liu \\ Faculty of Foreign Languages \\ Huaiyin Institute of Technology \\ Huai' an, China
}

\begin{abstract}
With English the increasingly dominant language across the globe, it is of tremendous significance for college students to have a good mastery of oral English as an instrument in the workplace as well as other applied skills. This paper investigates the feasibility of incorporating PBL into college oral English courses through elaborating on its definition, characteristics and advantages. The author also takes one unit themed career from her oral English class as an instance to demonstrate how the real implementation of PBL overcomes the problems existing in the course and facilitates the learning activities of the students.
\end{abstract}

Keywords-PBL; oral English teaching; constructivism; case study

\section{INTRODUCTION}

As the world becomes increasingly globalized and interconnected economically and culturally, Chinese college students are being confronted with both unprecedented opportunities and challenges. On the one hand, given advanced technology and various online resources, they can have easier access to uncountable information and massive knowledge. On the other hand, the questions as to how to make the best of these knowledge and how to put it into practice in real world have been on the spotlight. The traditional way of transporting knowledge from the textbook into the workplace has been outmoded and the employers have come up with more demands for their prospect employees.

"Table I" (McLester, S., \& McIntire, T., 2006) reveals to us the basic knowledge and applied skills in the workplace that the employers are anticipating.

In the past decades, western educators have identified PBL as an effective method of teaching and learning which has its inherent advantages over other approaches when it comes to increasing students'motivation and engagement, promoting creativity and critical thinking as well as cultivating other applied skills. And numerous scholars and researchers have combined PBL with studies or reforms about almost all the disciplines. ESL is no exception. In China, college English teaching is being confronted with the same challenges as other disciplines so a variety of curriculum reforms have been unfolded to transform English courses into being more compatible to ever-changing society so as to provide graduates with more competence at workplace.owing to the consistent efforts, satisfying results have been produced and remarkable progress have been made. And in the past decade, PBL with its unique edges has made its contributions to the reform in this field. However, compared to other aspects of English learning such as reading and writing, it is widely known that oral English courses are faced with more challenges and difficulties on account ofvarious reasons. Thus in this paper, the author tries to combine PBL method with oral English teaching with a case study of adopting PBL into a specific unit of the textbook and comes up with some real problems to tackle for the future study.

\section{TABLE I. SKILLS NEEDED IN TODAY'S WORKPLACE}

\begin{tabular}{|l|l|}
\hline Basic knowledge & Applied skills \\
\hline English language & Critical Thinking and Problem \\
Reading Comprehension & Solving \\
Writing & Written Communications \\
Mathematics & Teamwork and Collaborations \\
Science & Diversity \\
Government and Economics & Technology Application \\
Humanities and Arts & Leadership \\
Foreign Languages & Creativity and Innovation \\
History and Geography & Lifelong learning and Self-direction \\
& Professionalism and Work Ethic \\
& Ethics and Social Responsibility \\
\hline
\end{tabular}

II. INTRODUCTION OF PBL

\section{A. Definition of PBL}

Though in the past 100 years, schools in America have established the tradition of getting students to "do projects" rather than "acquire knowledge by rote", it is not the same thing with PBL discussed by researchers nowadays. A more definitive and systematic concept or model that is easy to be followed by instructors, of whose effectiveness can be measured as well is called for in educational field. Contributions have been made by various educators and researchers to polishing up the theory of PBL though no universally accepted definition has been given. However, it can be generalized as a learning activity where students get engaged attentively in the project by pursuing the solutions to certain real-life problems and at the same time master social skills and improve capability at workplace. 
In this paper, the author adopts the definition of PBL given by the Buck Institute for Education: "PBL is a teaching method in which students gain knowledge and skills by working for an extended period of time to investigate and respond to an engaging and complex question, problem, or challenge."

Firstly, In PBL, students will view the learning task they are dealing with is meaningful to them, enabling themselves to be motivated enough to sustain through the whole questioninvestigation and task fulfilling process; secondly, a welldesigned and well-implemented task can fulfill the teaching purpose ultimately, students gaining both comprehensive knowledge and applied skills.

\section{B. Criteria of $P B L$}

Although no universallyaccepted definition has been presented with regard to $\mathrm{PBL}$, researchers have basically agreed on certain nature or criteria that define an authentic PBL. A set of five basic criteria have been offered to follow (John W. Thomas, 2000): "centrality, driving question, constructive investigations, autonomy and realism".

"Centrality" means that students must learn the new concept through engaging directly into the project. Therefore, PBL serves as a integrated system where students get immersed rather than just a tool to help realize the final educational purpose. It needs to be inclusive so that everything that falls out of the project can not be regarded as the outcome or results of it.

"Driving question" is what drives forward the learning process and integrates a variety of activities and disciplinary knowledge naturally, a question around which students conduct investigation and to which they pursue the answer.

It is widely acknowledged in the past decades that the teaching ideology of "constructivism" have shed lights on the exploration of teaching activities in class and is contrast to the traditional "objectivism learning mode"which identifies knowledge acquisition is separatedfrom the learner rather than an active process of the learner of linking the prior experience and the new knowledge and then reconstructing the newlygained knowledge into his or her knowledge system(Von Glasersfeld, E., 1995). It indicates that if a project is so simple or "hands-on"that it only demands a small amount of cognitive efforts of the students, which can by no means be in accordance with the notion of PBL, which focuses on the comprehensive adoption of students'applied skills.

"Autonomy"means students must be the center and the project must carry on automatically like a real-life one rather than a preset problem needed to be solved with fixed answers or approaches to that. During the process of implementing the project, teachers need to supervise from above instead of monitoring the procedure closely from time to time. Students need to engage actively in the process of making research plan around certain topic, searching for data and information, investigating on the phenomenon and coming out with the solution or outcome analysis

"Realism", or "authenticity", indicates that the whole project must generate a sense of authenticity instead of making students feel artificial. Every single element embodied in the project from the topic set, the problem presented, the situation provided, to the tools adopted, solutions or products come up with and evaluation or feedback given to the students, must be realistic.

Besides the five criteria mentioned above, there are some other guides as well. For example, it is of great necessity for students to conduct collaborative learning, where they will find and enjoy the benefit of teamwork. Besides, most of the time, students need to present their product to the public, oral report, group display, etc. And moreover, both the teacher and students might as well cultivate the habit of reflect on the whole process of the project, like the plan, the tools, the product, the learning process, to see whether there are some parts which they can modify or improve.

\section{Merits and Demerits of PBL}

PBL has its inherent advantages over other forms of learning despite the fact that so far there isn't sufficient research conducted on to what extent it is gaining edges over other methods and also empirical statistics or data is far from adequate with respect to the evaluation or assessment of the outcomes. However, an increasing amount of evidence helps illustrate the truth that PBL does prove to be a helpful instrument to teacher instructing students and students' autonomous studying, which encourages a growing number of teachers to shift their attention to it from other traditional teaching approaches.

Merits can be concluded into the following aspects. 1) It can raise the students' interests in learning and boost motivation. School courses are no longer dull and meaningless in their eyes and passive learners turn into active learners, thus encouraging them to explore the answers to complicated questions. 2) It can transform students' way of learning and be conducive to the digestion of learning content. Through PBL, students can understand the content much better than traditional way of mechanic memorizing, thus restructuring the newly-acquired knowledge into their prior cognitive system and later applying it into real situation. 3) It contributes to the cultivation of students' comprehensive abilities such as cooperation, investigation, problem solving and critical thinking, which are beneficial not only to the students at college, but also to the graduates at workplace. 4) PBL helps facilitate the shift of teachers' role and is conducive to the reform and innovation of the classroom teaching. Teachers through PBL can regain the pleasure of learning along withtheir students without keeping an eye on every procedure and giving specific instruction.

It is undeniable that PBL like other methodologies has its own disadvantages. First of all, the teachers find it quite challenging to change their role fundamentally in the process of implementing PBL. On the one hand, some of them are used to the traditional way of lecturing, unwilling to give up their authority of knowledge. On the other hand, some teachers incline to overrate it, allowing students to take charge of the whole class all the time communicating and discussing without giving instruction or providing proper guides, letting the class slide into disorder. Secondly, it is of great challenge for both 
teachers and schools to implement PBL due to various condition limitations. For teachers, adopting PBL means more efforts and energy need to be put into the preparing of the class, the effective instructing during students' automatic learning and also the proper evaluation of the their products. For schools, difficulties also come in a variety of kinds. For example, the question as to how to assign enough instructors to every group and the problem of limited resources both in paper form and in multimedia form.

\section{Process of Implementing PBL}

So far various procedures of conducting PBL have been provided by different educational experts and institutes. In this paper, the author summarizes them into five steps as illustrated in "Fig. 1".

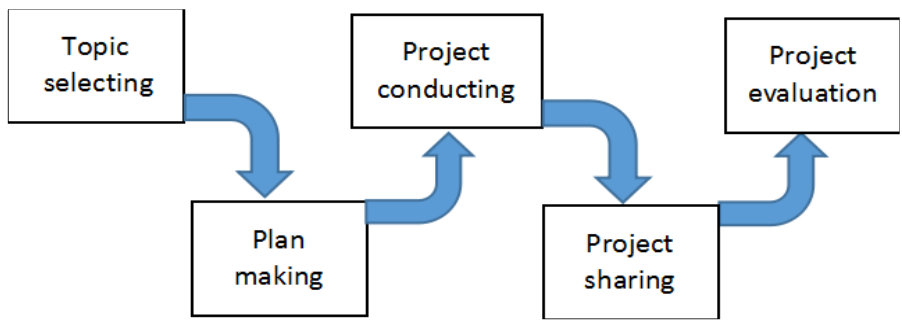

Fig. 1. Process of implementing PBL

\section{Step one: Topic selecting}

Adequate high-quality preparation of the teacher prior to unfolding the project is of tremendous significance. The teacher still needs to dig into the learning goals of each unit of the course and think about what kind of knowledge and skills to be gained and developed after this class. Thus the driving question or project should be designed centered on these objectives instead of overlooking them. An effective driving question is beneficial to the teacher in guiding the plan making process of his or her students. Moreover for the students, a good driving question facilitate getting themselves focused on the project itself, making sure they are very clear on the objective of the project and not distracted by other trivial. In this part, the teacher also defines the criteria of assessment and evaluation to facilitate students' reflecting on the effectiveness of the result in the end.

\section{Step two: Plan making}

In this step, students will be grouped under different topics and get familiar with each other. They need to study the question and reflect on the kind of problems they might encounter in the whole process and the resources they may utilize. In addition, each member of every group should be aware of both his strength and his shortcoming, like what he is best at and in what area he may need to make additional efforts. In this part, it is essential for the teacher to offer practical and theoretical support, e.g problem solving strategies and proper explanation of certain concepts that are difficult to interpret or easy to be confused, to ensure that each group exactly understand the task they are going to handle.

Step three: Project conducting
In this section, the learners will unfold a series of activities to complete the project, both collectively or individually. When they launch the project, they engage in a real situation where problems are authentic and they need to accumulate information or data, master corresponding knowledge and skills and make best of resources to address the obstacles. During the process, the teacher does not need to provide with direct instructions. Instead, he or she may take on the role of a coach or a facilitator outside the "playground"to enable students to be creative and motivated.

\section{Step four: Product presenting or sharing}

After carrying on the project, learners must present their learning results through the approach of PBL to others including the teacher, the rest of the class and maybe the community involved in a variety of forms, demonstrating the result through PowerPoint, giving oral report, making poster, etc. The specific kind mainly depends on the nature of the task itself and the teacher needs to make proper adjustment based on the real situation.

\section{Step five: Product evaluation and feedback}

To evaluate the effectiveness of the result of learning through PBL, the teacher needs to review with the students all the criteria he or she sets at the beginning to check if the learning purposes of this unit have been met. A variety of evaluation methods can be adopted like self-evaluation, peer evaluation, group discussion and teacher feedback. When examining the final outcome, the teacher needs to base the assessment on not only the final product, but also the process itself and keep questions like the following ones in mind: do the students master the knowledge and skills? Do they cooperate in the process and how do they handle differences in opinions? Do they choose the right media to present the outcome? Where can they make further improvement and construct the newly-gained knowledge into their previous cognitive systems?

\section{INCORPORATING PBL INTO COLLEGE ORAL ENGLISH Class}

Consensus has been reached on the notion that with English becoming the dominant language across the globe, it is of much necessity for college students to have a basic mastery of it, especially for those who have the intention to enter international companies or pursue further study abroad. To meet such demand, colleges in China open a series of basic English courses such as College English, Oral English, English Writing, etc. However, debates and questions have been arising regarding the way English is taught in the college: how should it be differentiated from that in schools prior to college? And how do college students view and evaluate college English teaching: is it all about teachers explaining the knowledge points in text or PPT and preparing students for the CET 4, or is it an engaging process students find challenging yet rewarding?

Moreover compared to other aspects regarding English learning, the oral English class lays more emphasis on cultivating students' practical ability to communicate and cooperate with others in real-life situation, thus posing greater 
challenge to and asking more from English teachers. It has been well established and publicly agreed by teachers that a good oral English class should be topic-based and studentscentered, which can boost students' confidence and make them more active in class. However, in most cases, a number of problems may arise worth of attention of English teachers.

\section{A. Present Problems in College Oral English Teaching}

1) Teacher-oriented teaching method: Despite the fact that teachers try their best to make students 'the master of the class', the effect turns out less satisfactory to everybody. On the one hand, teachers may find it difficult to spice up a class of more than forty students and give everyone enough attention and advice, let alone to get each student to complete certain real-life task. On the other hand, students themselves can not get fully engaged in the task due to limited preparation time in class and lack of coach from the teacher. So normally an oral English class is made up of the following two parts: listening to the recording and making your own conversation in pair, which no doubt usually is a simple imitation of the recording. Simply giving students more chance to speak English in class doesn't necessarily mean the class has become student-oriented like the course syllable has required.

2) Outdated teaching content: Though the textbook has evolved continually according to the course requirement, the traditional modules have not been totally reorganized according to the real world situation. For example, students still need to follow the old-school catalog: first date and number, then weather and sports, at last work and society. Compared to what students have learned from high school oral English class, maybe the only difference lies in the fact that there appear more difficult vocabulary, which basically can not arouse students' interest any more who mostly choose this course to improve their practical ability yet to find out they don't have much space to move forward. The author finds that in most cases that after class students only find themselves able to learn several new words, which will be totally forgot in the next class. An increasing number of teachers try to ask students to make some PPTs around certain topic. However, most of the students do not know the real purpose behind this task and only read their PPTs out loud in front of the class, which also brings them no good.

3) Limited in-class resources: This can be the most awkward problem for the teacher and students in an oral class. Usually one class consists of 90 minutes and the teacher needs to finish one unit with students in accordanceto the syllabus. However, students need to accomplish multitasks in one class like listening, making up conversation, watching videos, etc. Given that a class is usually made up of more than twenty groups, it is not difficult to notice that students do not have enough time to prepare any task in depth and the teacher does not have sufficient time to give feedback to students on their performance. Thus, in most cases, what each group does is basically similar with several simple greetings and exchange of information which is not able to mirror the real world situation. What most of the teachers do resemble each other: correction of the vocabulary and the wrong pronunciation.

4) Over-simplified concept of "topic": In most oral English classes, topic-based tasks are overused yet rarely touch the essence of it. It is not only a few times that the students complain about the topics they are talking about are out-of-date and lack originality, which they are already familiar with from high school and may not come at handy when they are at workplace. All these prove that the topic teacher gives the students to practice on is rather simplified and only focuses on one aspect of real life, e.g. talking on the phone or talking about the weather. However, in the real situation, graduates may come across various problems like applying for a job, going for an interview,etc. Therefore, it is advisable to spice up the 'topic' a little bit by 'mixing up' different topics and integrate them into a single 'project', and to guide the students to finish the project by themselves.

Given the special status and practical obstacles of oral English courses at present, it is of enormous realistic significance to combine it with PBL. Used properly, PBL can make the English class more engaging and motivating, spicing up the atmosphere and boost students' interests. However, PBL does not only mean games and fun, teachers need to consider how to make a good balance between creating authentic situation which can motivate the students and letting students master the real and useful knowledge. In the following section, an example from the author's work in the university oral English class will be given to illustrate how can PBL helps facilitate the oral English teaching and learning activity.

\section{B. Example of Implementing PBL in Oral English Class}

The author is going to take the unit8 "Career"in the book "Inspired to Speak" as an example in her oral English class to demonstrate how PBL is integrated into an oral English class. The whole unit consist of three sessions, 150 minutes in total and the class constitutes 36 persons. In the first session, the teacher divides the students into 6 groups with 6 persons in each group. Then the teacher demonstrates the six driving questions under the theme "career"for the students to tackle.

- Establish a mock university career planning and development center and unfold a series of activities about employment instruction for the prospective graduates and publicize the activities on campus.

- Organize a job interview for a world top 500 company with two position vacancies.

- Conduct a survey about university students' job preferences, analyze the outcome and give an oral report.

- Introduce two of the most popular jobs nowadays including information like training requirements, advancement opportunities and salary and benefits. 
- Conduct a survey about university students' intention of starting their own business, analyze and present the result.

- Do research on the whole process of starting one's own business and present it to the class.

The teacher explained each question in details and helped students figure out the specific purpose of each task and helped the students to locate the right place in the book for further reference.

In the second session, the group members needed to assign different parts of the task to themselves based on their own strength like who was responsible for searching for and accumulating information, who was making visual of the result and who was presenting the project to the class. Each task was made up of several small tasks and every member took charge of different one. As a result, it was crucial for each one to finish his or her task on time individually and also learn to cooperate to ensure the task can be accomplished in time. In the process of conducting the project, it was vital for students to resort to all sorts of resources, online or in real life, to gather information and learn to differentiate information that may be conducive to their study from those that are not. They would learn to use software to analyze and evaluate the result and draw graphs. The third session included the product sharing part where students were able to demonstrate their project in a variety of ways. Before that, they needed to interpret their understanding of the topic and their thoughts of design. For example, in this part, the first group designed a delicate manual in which a great amount of employment instruction was offered as well as all other hands-on information with appendix of employers' recruitment information. And the second group presented to the audience an authentic interview, with one was human resource director, one was the manager, and the rest four were all candidates for the interview. In the interview, the interviewers welcomed the interviewees and gave a brief description of the requirements of the two vacant positions and then gave the floor to the candidates who later elaborated on their strength and other related information. Finally in the last session, the author adopted the group member evaluation, peer evaluation combined with teacher evaluation. The teacher kept a close eye on the whole process and took notes of the problems that arose in the process and the parts where improvement could be made. The grades students got from conducting the project were counted as the grades for their after-class assignment. After the project, the author also collected feedback from her students on their evaluation of learning through the methodology of PBL to see whether they were capable of adapting themselves to the new approach.

\section{CONCLUSION}

In this paper, the author presents an in-depth introduction of PBL including its definition, characteristics, merits and demerits. Then the problems in real teaching situation facing university oral English courses are comprehensively discussed. Then an example has been given by the author as to how to incorporate the theory of PBL into a specific book unit. It is no doubt PBL has gained tremendous advantages over other teaching and learning methodologies from the perspective of equipping students with applied skills and standard knowledge as well as motivating students to search for the answers of authentic problems in real life. Therefore, it is of enormous significance to implement PBL in the oral English classes. However, in the process of implementing PBL, the author was encountered with various kinds of problems from different perspectives. As to student participation, admittedly, compared to the traditional class, the class with the adoption of PBL is filled with incredible creativity and vigor where students are more motivated and engaged. However, the degree of participation varies from person to person. Some students refused to seek answers for themselves; instead, they wanted others to share with them. Someone was always behind the schedule and thus it influenced the progress of the whole team. In terms of classroom resources, a number of creative ideas and designs of students could not be put into practice and the outcome of the product could not be presented to the greatest degree due to limitation of materials like outdated multimedia, access to the Internet. As for the time allotment, the teacher found that the present class session allotment can not meet the demand of conducting PBL and that students needed to be assigned more time to present their outcome and reflect on the effect. It is also very challenging to assess the students' performance in PBL implementing. Unlike the traditional evaluation methods like having a test, doing a quiz, assigning homework, a great number of vital sections in PBL is unable to measure. For example, questions like how the team collaborate, to what degree the basic knowledge is acquired, whether it is necessary to introduce external expert in society to help evaluate the work are all noteworthy. It is advisable that in future more research be done in order to address the practical problems in integrating PBL into university oral English classes.

\section{REFERENCES}

[1] McLester, S., \& McIntire, T, "The workforce readiness crisis," http://www.chetek.k12.wi.us/highschl/newsfile1065_1.doc, 2006.

[2] Thomas, J.W., "A Review of Research on Project-based Learning," Report prepared for the Autodesk Foundation. http://www.bie.org/index.php/site/RE/pbl_research/29, 2000.

[3] Von Glasersfeld, E., Radical Constructivism: A Way of Knowing and Learning. London: Falmer Press, 1995. 